\title{
Charge Density and Molecular Weight of Polyphosphoramidate Gene Carrier Are Key Parameters Influencing Its DNA Compaction Ability and Transfection Efficiency
}

\author{
Yong Ren ${ }^{\dagger}$, Xuan Jiang ${ }^{\dagger}$, Deng Pan $\S$, and Hai-Quan Mao ${ }^{*}, \dagger$ \\ Department of Materials Science and Engineering, Whitaker Biomedical Engineering Institute, \\ and Institute of NanoBioTechnology, Johns Hopkins University, Baltimore, MD 21218; \\ Department of Biomedical Engineering, Johns Hopkins University, Baltimore, MD 21218
}

\begin{abstract}
A series of polyphosphoramidates (PPA) with different molecular weights (MWs) and charge densities were synthesized and examined for their DNA compaction ability and transfection efficiency. A strong correlation was observed between the transfection efficiency of PPA/DNA nanoparticles and the MW and net positive charge density of the PPA gene carriers in three different cell lines (HeLa, HEK293 and HepG2 cells). An increase in MW and/or net positive charge density of PPA carrier yielded higher DNA compaction capacity, smaller nanoparticles with higher surface charges and higher complex stability against challenges by salt and polyanions. These favorable physicochemical properties of nanoparticles led to enhanced transfection efficiency. PPA/DNA nanoparticles with the highest complex stability showed comparable transfection efficiency as PEI/DNA nanoparticles likely by compensating the low buffering capacity with higher cellular uptake and affording higher level of protection to DNA in endolysosomal compartment. The differences in transfection efficiency were not attributed by any difference in cytotoxicity among the carriers, as all nanoparticles showed minimal level of cytotoxicity under the transfection conditions. Using PPA as a model system, we demonstrated the structural dependence of transfection efficiency of polymer gene carrier. These results offer more insights into nanoparticle engineering for non-viral gene delivery.
\end{abstract}

\section{Keywords}

Polymeric gene carrier; DNA nanoparticles; charge density; molecular weight; transfection efficiency

\section{Introduction}

\begin{abstract}
Polymeric gene carrier as an alternative to viral counterpart offers significant advantages including better safety profiles, more versatile payload capacity and more tunable physiochemical properties of the delivery vehicle. 1,2 A variety of polycations have been reported as gene carriers. Notable examples include poly(amino acid)s, ${ }^{3,} 4$ polyamide, 5 polyethylenimine, 6 poly $\left(\beta\right.$-amino ester)s, ${ }^{7}$ polysaccharides ${ }^{8}$ and polyphosphoesters. ${ }^{9}$ All of these polymers possess amino groups, at least a portion of which are protonated at neutral
\end{abstract}

\footnotetext{
"Corresponding author: Hai-Quan Mao, 101E Maryland Hall, 3400 North Charles Street, Baltimore, MD 21218, U.S.A. Tel: (410) 516-8792; Fax: (410) 516-5293;hmao@jhu.edu.

†Department of Materials Science and Engineering

$\S_{\text {Department of Biomedical Engineering }}$
} 
$\mathrm{pH}$, mediate transfection via electrostatically driven self-assembly with DNA into particles or complexes with sizes in the range of tens to hundreds of nanometers. These polymer/ DNA particles mediate transfection by a number of possible mechanisms, ${ }^{1}, 10$ which include protecting DNA from enzymatic degradation, facilitating cell uptake, promoting endolysosomal escape, modulating DNA unpacking in cytosol and nucleus, and escorting nuclear translocation of DNA or nanoparticles.

Despite the fact that a large number of cationic polymers have been used as gene carriers, the structure-property relationship, and more specifically, the key parameters of gene carriers for successful gene delivery, remain elusive. Among other parameters, the type ${ }^{11}$ and density of charge groups, ${ }^{12}$ the hydrophilicity/hydrophobicity balance, 13,14 chemical structure, 15,16 molecular weight (MW), ${ }^{14}, 17,18$ the ability of DNA release 1 and degradability ${ }^{19,20}$ of the cationic polymer are considered important to the optimization of DNA compaction, polymer/DNA nanoparticle properties and transfection efficiency. ${ }^{2}$ There have been several conflicting reports on the effect of MW on transfection. Generally speaking, the gene expression increased with increasing MW of polycation. ${ }^{14}$ For instance, Layman et al. reported that a dramatic increase in luciferase expression was observed as the weight average molecular weight of PDMAEMA increased from $43 \mathrm{kDa}$ to $915 \mathrm{kDa}$ in human brain microvascular endothelial cells. ${ }^{17} \mathrm{Yu}$ et al. Reported that the largest bioreducible PEI ( $37 \mathrm{kDa}$ ) demonstrated highest transfection levels among all the PEI they used in B16-F10 (murine melanoma cells) and CHO-K1 (Chinese hamster ovary cells) cells. 21 However, there are also some exceptions. Transfection efficiency mediated by chitosan of $100 \mathrm{kDa}$ was less than that by chitosan of 15 and $52 \mathrm{kDa}$ in Human-lung carcinoma A549 cells, B16 melanoma cells, and HeLa cells.22 Low molecular weight branched PEI (11.9 $\mathrm{kDa}$ ) yielded a transfection efficiency that was up to two orders of magnitude higher than that obtained with higher MW PEI ( $800 \mathrm{kDa})$ in ECV304 cells.23 On the other hand, there are also different opinions on the effect of charge density on transfection. Kiang et al. reported that the decreased degree of deacetylation (charge density) of chitosan resulted in a decrease in overall luciferase expression levels in HEK293, HeLa, and SW756 cells. ${ }^{24}$ But Lee et al. showed that poly(glycoamidoamine)s with higher amine density in the repeating unit did not significantly enhance the transfection efficiency compared with that with lower positive charge density. ${ }^{25}$

Polyphosphoesters and polyphosphoramidates have been investigated as biomaterials for almost two decades, initially in drug delivery and more recently in gene delivery. The unique advantage of polyphosphoester gene carriers is their structural versatility-the pentavalency of phosphorus atoms in the backbone of polyphosphoester makes it possible to conjugate different functional groups as side chains, with identical backbone and consistent molecular weight (MW). Thus it provides a convenient carrier platform for studying the structure-function relationship systemically. Polyphosphoesters bearing charged groups through a phosphate $[-\mathrm{P}(\mathrm{O})-\mathrm{O}-] 9,26,27$ or a phosphoramide $[-\mathrm{P}(\mathrm{O})-\mathrm{NH}-] 28$ bond as side chains have been proven to be efficient gene carriers. We have previously examined a series of cationic polyphosphoramidates (PPAs) with identical backbone and side chain spacer length but different types of charge group (primary, secondary, tertiary and quaternary amino groups), and demonstrated that PPA carriers with primary amino groups were most efficient compared with other types of charged groups. 29 Furthermore, we have recently shown that PPAs with branched side chains exhibited much higher gene transfer efficiency than those with linear side chains, based on assessing a series of PPAs that have an identical backbone bearing primary charge groups on the side chains with different side-chain structures.

In this report, we show that MW and net positive charge density of polycationic PPAs are the key parameters to influence the compaction ability to DNA, hence affect the protection 
to DNA, cellular uptake level and transfection efficiency of PPA/DNA nanoparticles in vitro. These results also help to uncover the mechanism and major barriers to transfection mediated by PPA.

\section{Experimental Section}

\section{Materials}

Polyethylenimine (PEI, branched, MW $25 \mathrm{kDa}$ ), carbon tetrachloride $\left(\mathrm{CCl}_{4}\right), \mathrm{N}, \mathrm{N}-$ dimethylformamide (DMF), dichloromethane (DCM), triethylamine (TEA), dipropyltriamine (DPA), triisobutylaluminum (TIBA), ethidium bromide and all other reagents were purchased from Sigma-Aldrich (St. Louis, MO), unless otherwise specified. Fetal calf serum and fetal bovine serum were purchased from HyClone (Logan, UT). Penicillin-streptomycin and Dulbecco's Modified Eagle's Medium (DMEM) were purchased from Invitrogen (Carlsbad, CA). $\mathrm{N}^{1}, \mathrm{~N}^{9}$-bis(trifluoroacetyl)dipropyltriamine (TFA-DPA) was synthesized according to the procedure reported by O'Sullivan et al. ${ }^{30}$ The cyclic monomer 4-methyl-2-oxo-2-hydro-1,3,2-dioxaphospholane was prepared as reported previously. ${ }^{28}$

\section{Amplification and purification of plasmid DNA}

VR1255C is a 6.4-Kb plasmid DNA encoding firefly luciferase driven by the cytomegalovirus (CMV) promoter (a gift from Carl Wheeler, Vical, San Diego, CA). The plasmid was amplified in Escherichia coli DH5 $\alpha$ and purified by an endotoxin free QIAGEN Giga plasmid purification kit (QIAGEN, Valencia, CA) according to manufacturer's protocol. Purified DNA was dissolved in Tris-EDTA buffer, and its purity and concentration were determined by UV absorbance at 260 and $280 \mathrm{~nm}$ and by gel electrophoresis.

\section{Synthesis and characterization of polyphosphoramidate (PPA) polymers}

The synthesis of PPAs with DPA side chain, hereafter termed PPAs, was summarized in Scheme 1. TIBA ( 1 м in hexane, $0.2 \mathrm{~mL}$ ) was dissolved in $20 \mathrm{~mL}$ of anhydrous dichloromethane in a pre-dried reaction vessel under argon. The polymerization of 4alkyl-2-oxo-2-hydro-1,3,2-dioxaphospholane (1) was initiated by injecting $5.4 \mathrm{~g}$ of the monomer into initiator solution under ice-water bath. The mixture was stirred at $0{ }^{\circ} \mathrm{C}$ for 48 $\mathrm{h}$. The precursor polymer (2) was obtained by removing solvent under vacuum at room temperature. The precursor polymer was then dissolved in $40 \mathrm{~mL}$ of anhydrous DMF under argon. To this solution was added $37.8 \mathrm{~g}$ of TFA-DPA, followed by addition of $48 \mathrm{~mL}$ of anhydrous TEA and $33 \mathrm{~mL}$ of anhydrous $\mathrm{CCl}_{4}$. The mixture was stirred at $0{ }^{\circ} \mathrm{C}$ for $30 \mathrm{~min}$ then at room temperature for $24 \mathrm{~h}$. The reaction mixture was filtered, precipitated into ether and then dried under vacuum to yield polymer (3). Polymer (3) was suspended in $20 \mathrm{~mL}$ of $25 \%$ ammonia solution and stirred at $60{ }^{\circ} \mathrm{C}$ overnight. The solution was concentrated and dialyzed in dialysis tubing (MWCO 3500, Spectrapor, Spectrum Labs, CA) against deionized (DI) water for 2 days with frequent water change. PPA (4) was obtained by lyophilization (yield 30-40\%). The MW of PPA was determined using an Agilent 1200 Series Isocratic LC System equipped with PL aquagel-OH 30 8- $\mu \mathrm{m}$ column and PL Aquagel-OH MIXED 8- $\mu$ m column (Polymer Laboratories Ltd), which was connected with a multi-angle light scattering detector (MiniDawn, Wyatt Technology, Santa Barbara, CA). A $d n / d c$ value of 1.4 was used for all PPA samples. Sodium acetate buffer (HAc 0.5 м and $\mathrm{NaAc} 0.5 \mathrm{~m}$ ) was used as mobile phase with a flow rate of $0.5 \mathrm{~mL} / \mathrm{min}$.

\section{Buffering capacity of PPA}

The buffering capacity of PPAs was determined by acid-base titration. An amount of PPAs that is equal to $0.1 \mathrm{mmol}$ of amine groups was dissolved in $5 \mathrm{~mL}$ of $0.15 \mathrm{M} \mathrm{NaCl}$ solution. 
The $\mathrm{pH}$ of polymer solutions was initially set to $\mathrm{pH} 11.0$ by $2{ }_{\mathrm{m}} \mathrm{NaOH}$ and titrated to $\mathrm{pH} 3.0$ by using $0.1 \mathrm{~m} \mathrm{HCl}$. BPEI $(25 \mathrm{kDa})$ and $0.15 \mathrm{~m} \mathrm{NaCl}$ solutions were titrated in the same way as controls. The $\mathrm{pH}$ of the solutions was measured after each addition by a $\mathrm{pH}$ meter (Fisher Scientific Accumet AB15 Basic and BioBasic pH Meters). The buffering capacity is defined as the percentage of amine groups that become protonated from $\mathrm{pH} 7.4$ to 5.1 and calculated using the following equation:

$$
\text { Buffering capacity }(\%)=\left(\delta \mathrm{V}_{\mathrm{HCI}} \times 0.1 \mathrm{M}\right) / 0.1 \mathrm{mmol} \times 100 \%
$$

whereas $\delta \mathrm{V}_{\mathrm{HCl}}(\mathrm{mL})$ is the volume of $\mathrm{HCl}$ solution $(0.1 \mathrm{~m})$ which brought the $\mathrm{pH}$ value of polymer solutions from 7.4 to 5.1. The relationship between $\mathrm{pH}$ and protonation degree of polymers was determined from the obtained titration curve.

\section{DNA compaction ability of PPA}

The fluorescence intensity of the polymer/DNA nanoparticles was evaluated using the ethidium bromide fluorescence assay. VR1255 DNA solution $(100 \mu \mathrm{g} / \mathrm{mL}, 50 \mu \mathrm{L})$ in DI water was added to an equal volume of PPA solution in DI water at N/P ratio 10 or 16, respectively. After incubation for $30 \mathrm{~min}$, the nanoparticle was added to a 96 -well plate for fluorescence at the dose of $1 \mu \mathrm{g}$, followed by ethidium bromide $(80 \mu \mathrm{L}$ of $3.75 \mu \mathrm{g} / \mathrm{mL}$ solution in PBS). DNA solutions with different concentration were used as calibration. The fluorescence intensity $\left(\lambda_{\mathrm{ex}} 530 \mathrm{~nm}, \lambda_{\mathrm{em}} 610 \mathrm{~nm}\right)$ was measured on a fluorometer (SpectraMax Gemini XPS, Molecular Devices, Sunnyvale, CA). The relative fluorescence intensity values were calculated according to the calibration curve.

\section{Size and zeta potential of PPA/DNA nanoparticles}

Particle size and zeta potential were measured by photon correlation spectroscopy and laser Doppler anemometry, respectively, using a Zetasizer Nano ZS90 (Malvern Instruments, Southborough, MA, USA). Size measurement was performed at $25^{\circ} \mathrm{C}$ at a $90^{\circ}$ scattering angle. The mean hydrodynamic diameter was determined by cumulative analysis. The zeta potential measurements were performed using a DTS1060-folded capillary cell in the automatic mode.

\section{Cellular uptake of PPA/DNA nanoparticles}

DNA was labeled with YOYO-1 iodide at ratio of 1 molecule of the dye per 50 base pairs of the nucleotide. HeLa (a human cervical cancer cell line), HEK293 (a human embryonic kidney cell line) cells or HepG2 (a human hepatocellular carcinoma line) were transfected with PPA/YOYO-DNA nanoparticles at either $37{ }^{\circ} \mathrm{C}$ or $4{ }^{\circ} \mathrm{C}$. Cells were seeded $24 \mathrm{~h}$ prior to transfection in 24 well plates at a density of $4 \times 10^{4}$ (HeLa), $1.4 \times 10^{5}$ (HEK293) or $1 \times 10^{5}$ (HepG2) cells/well. Then $40 \mu \mathrm{L}$ of nanoparticles with equivalent DNA dose of $2 \mu \mathrm{g}$ were added to each well. The cells were incubated for $4 \mathrm{~h}$ either at $37^{\circ} \mathrm{C}$ or at $4{ }^{\circ} \mathrm{C}$, and then washed with cold PBS for 3 times, trypsinized and fixed with $1 \%$ paraformaldehyde. Fluorescence analysis was performed with a BD FACSCalibur flow cytometer (BD Biosciences) fitted with a $488 \mathrm{~nm}$ excitation source and detected using a 515-545 nm filter. A minimum of 10,000 events per sample were collected for analysis.

\section{Complex stability of PPA/DNA nanoparticles against dextran sulfate}

Complex stability was assessed in the presence of dextran sulfate with an average MW of $500 \mathrm{kDa} .{ }^{31}$ Nanoparticle suspension $(20 \mu \mathrm{L})$ was added to a 96 -well plate for fluorescence at the dose of $1 \mu \mathrm{g}$, followed by addition of dextran sulfate solution $(20 \mu \mathrm{L})$ at different concentrations and ethidium bromide $(60 \mu \mathrm{L}, 5 \mu \mathrm{g} / \mathrm{mL}$ in PBS). The fluorescence of the 
mixture was measured by the same method of ethidium bromide assay as described in DNA compaction assay.

\section{In vitro gene transfection of PPA/DNA nanoparticles}

In vitro gene transfection was performed in HeLa, HEK293 and HepG2 cells. All the cell lines were maintained in Dulbecco's Modified Eagle's Medium supplemented with 10\% fetal calf serum (FBS) at $37{ }^{\circ} \mathrm{C}$ and $5 \% \mathrm{CO}_{2}$. Cells were seeded in 24-well plates at the density of $4 \times 10^{4}, 1.4 \times 10^{5}$ and $1 \times 10^{5}$ cells per well, respectively, and incubated for one day. PPA/DNA nanoparticles were added to each well at a dose of $2 \mu \mathrm{g}$ of plasmid DNA in 0.5 $\mathrm{mL}$ of fresh medium with $10 \%$ FBS. After $4 \mathrm{~h}$ of incubation, the culture media were refreshed with medium with $10 \%$ FBS. Two days later, the culture media were removed, and cells were washed with $0.5 \mathrm{~mL}$ of phosphate buffered saline (PBS, $\mathrm{pH}$ 7.4). Cells were then lysed with a reporter lysis buffer $(0.2 \mathrm{~mL} /$ well, Promega, Madison, WI), and subjected to two freeze-thaw cycles. The suspensions were centrifuged at 14,000 rpm for $5 \mathrm{~min}$. Twenty $\mu \mathrm{L}$ of cell lysate supernatant was mixed with $100 \mu \mathrm{L}$ of luciferase substrate (Promega), and the light units were measured on a luminometer (20/20n Single Tube luminometer, Turner BioSystems, Sunnyvale, CA). The luciferase activity was converted to the amount of luciferase using recombinant luciferase (Promega) as the standard, and normalized against protein content using the BCA protein assay (Bio-Rad Laboratories, Hercules, CA). For the transfection in the presence of chloroquine, the cells were cultured with medium containing $50 \mu_{\mathrm{m}}$ of chloroquine after $4 \mathrm{~h}$ of transfection.

\section{Cytotoxicity of PPA/DNA nanoparticles}

Cytotoxicity of PPA/DNA nanoparticles were determined by WST-1 dye reduction assay. Cells were seeded in a 96-well plate $24 \mathrm{~h}$ before the assay at a density of $8 \times 10^{3}$ (Hela), $28 \times 10^{3}$ (HEK293) or $20 \times 10^{3}$ (HepG2) cells/well. The cells were incubated for $4 \mathrm{~h}$ with 100 $\mu \mathrm{L}$ of DMEM medium complemented with $10 \%$ fetal bovine serum (FBS) containing PPA/ DNA nanoparticles at a DNA dose of $0.4 \mu \mathrm{g} / \mathrm{well}$. The medium in each well was replaced with $100 \mu \mathrm{L}$ of fresh complete medium containing $10 \mu \mathrm{L}$ of WST-1 reagent (Roche, Mannheim, Germany). The cells were incubated for $1 \mathrm{~h}$ at $37^{\circ} \mathrm{C}$. The absorbance of the supernatant at $450 \mathrm{~nm}$ (using $600 \mathrm{~nm}$ as a reference wavelength) was measured on a microplate reader (Infinite M200, TECAN, Männedorf, Switzerland).

\section{Results and Discussion}

\section{Synthesis and characterization of PPA gene carriers}

Among various types of side chain structures of PPAs tested previously, ${ }^{2}$ dipropyl triamine (DPA) rendered PPA the most efficient carrier. Hence we choose this structure as a model to characterize the effect of MW and net positive charge density on transfection efficiency of PPA/DNA nanoparticles. Synthesis of PPA polymers was conducted according to the method that we reported previously. ${ }^{31}$ The efficiency of grafting reaction [TFA-DPA with (2)] was far less than $100 \%$ due to the steric hindrance (see Scheme 1). As a result, the grafting degree of polymers (3) and (4) was typically less than $70 \%$. The remaining portion of the repeating units in polymer (4) was hydrolyzed and carried negative charges along the polymer chains. Normally the tuning of charge density of polycation was carried out by adjusting acylation/deacylation of the amine group ${ }^{24}$ or distance between two charges. ${ }^{25}$ These may also change the hydrophobicity/hydrophilicity balance of the polymer. But in our case three positive charges were introduced to the PPA polymer for each DPA side chain, which means less hydrophobicity/hydrophilicity balance was changed when we tuned the charge density. This unique structure of PPA offers an opportunity to evaluate the effect of charge density of the gene carrier on its DNA compaction ability and transfection efficiency. In this study, we synthesized two sets of PPA carriers as shown in Table 1: one set had a 
similar grafting degree of 50\%, but with different average MWs or degrees of polymerization $(n)$; and another set had a similar backbone length (degree of polymerization $n$ ranged from 124 to 146), but with different grafting degrees (50\%-65\%). The degree of polymerization of the precursor polymer (2) was controlled by varying the monomer to initiator ratio. After polymerization, we varied the feeding ratio of TFA-DPA (and TEA and $\mathrm{CCl}_{4}$ ) to polymer to obtain PPAs with different grafting degree of DPA side chains that carried positive charges. The MW of PPA was characterized by GPC equipped with a static light scattering detector. The composition of PPA was confirmed by ${ }^{1} \mathrm{H}-\mathrm{NMR}$. The grafting degree (Scheme 1), which determines the theoretical average net positive charge density of PPA polymer, was obtained by compare the integral of peaks at $\delta 1.1-1.4 \mathrm{ppm}\left(\mathrm{C} \underline{H}_{3}\right.$ in the backbone) with that at $\delta 1.6-2.0 \mathrm{ppm}\left(\mathrm{CH}_{2} \mathrm{C}_{2} \mathrm{CH}_{2}\right.$ on the side chain).

Polymers P10-49, P15-50, P27-50 and P67-51, which had similar net positive charge densities, were used to investigate the effect of MW on nanoparticle formation and transfection efficiency. Another series of polymers P27-50, P25-56 and P31-65, which had similar chain lengths or degrees of polymerization, were used to investigate the effect of net positive charge density (Table 1).

\section{DNA Compaction ability}

Ethidium bromide intercalates into DNA base pairs and emits fluorescence at $610 \mathrm{~nm}$ when excited by $530 \mathrm{~nm}$ light. When polymers interact with DNA to form complexes, they condense DNA and then prevent the base pairs intercalating with ethidium bromide, which leads to a decrease in fluorescence intensity at $610 \mathrm{~nm}$. This assay is quantitative and the reduction of fluorescence correlates well to the DNA compaction ability of carriers. Figure 1 showed that the relative fluorescence intensity decreased from 0.38 to 0.28 , when MW of PPA increased from $10 \mathrm{kDa}$ to $67 \mathrm{kDa}$ at a fixed net positive charge density $(\sim 0.5)$ and an N/ $P$ ratio of 10. It implied that the DNA compaction ability of the PPA carrier increased with the increase of its MW. On the other hand, when the PPA chain length was fixed between 124 and 146, an increase in net positive charge density from 0.49 (P27-50) to 0.94 (P31-65) led to a drop of relative fluorescence intensity from 0.34 to 0.23 . This indicated that the DNA compaction ability of PPA increased with the net positive charge density. P31-65 carrier had the highest compaction ability among all the polymers tested, including PEI. Relative fluorescence intensity of PEI in previous report was around $10 \%,{ }^{32}$ which was much lower than $28 \%$ in our case. They were different because we tested the compaction ability in PBS instead of water. In general, the fluorescence intensity of the nanoparticles at an N/P of 16 was lower than that at N/P of 10, but showed the same trends as discussed above.

\section{Physiochemical properties of PPA/DNA nanoparticles}

Nanoparticle size is an important factor that influences cellular uptake of nanoparticles across the cytoplasmic membrane. ${ }^{33}$ The average size of PPA/DNA nanoparticles increased slightly when the number average MW of PPA increased from $10 \mathrm{kDa}$ to $67 \mathrm{kDa}$ at an N/P ratio of 10 or 16 (Figure 2a). On the other hand, the average size of nanoparticles dropped from $67 \mathrm{~nm}$ to $32 \mathrm{~nm}$, when the net positive charge density of PPA increased from 0.49 to 0.94 . Since the transfection was to be conducted under the physiological condition, we also measured the size of nanoparticles in $0.15 \mathrm{M} \mathrm{NaCl}$ solution to assess the stability of complex against the challenge of high ionic strength solution. We observed a 1.5- to 2-fold increase of average size for most of the PPA/DNA nanoparticles tested, with only the exception of P10-49 carrier. Two factors may contribute to the increase in particle size: particle swelling as a result of charge screening and particle aggregation due to colloidal instability. Since the particles carry net positive charges on their surface (zeta potential is +27 to $+39 \mathrm{mV}$ ), particle aggregation is less likely to happen in salt solution. Instead, charge screening in high 
ionic strength buffer $(0.15 \mathrm{M} \mathrm{NaCl})$ appeared to be the major reason for particle size increase. Accordingly, the DNA compaction ability of the carrier can influence the swelling behavior of the nanoparticles. The average size of P10-49/DNA nanoparticles increased by 4.5 times at $\mathrm{N} / \mathrm{P}$ of 10 and 3.2 times at $\mathrm{N} / \mathrm{P}$ of 16 in $0.15 \mathrm{M} \mathrm{NaCl}$ solution, in comparison with nanoparticles prepared in DI water. This observation is consistent with above analysis since P10-49 had the lowest MW and net positive charge density, in turn the lowest DNA compaction ability, which made P10-49/DNA nanoparticle less compact and more sensitive to ionic charge screening. In addition, complex stability of nanoparticles prepared at higher $\mathrm{N} / \mathrm{P}$ ratio was higher when tested in physiological salt concentration and $\mathrm{pH}$. This trend correlated well with the compaction ability of PPA carriers discussed above. We also characterized the change in nanoparticle size in response to salt challenge as function of time. The average sizes of PEI and P10-49 nanoparticles (N/P 10) increased with incubation time. In contrast, the average sizes of all other PPA/DNA nanoparticles maintained nearly constant for at least 4 hours when they were incubated with $0.15 \mathrm{M}$ of $\mathrm{NaCl}$ (Figure 2b). This result confirmed that PEI/DNA and P10-49/DNA nanoparticles were not stable in the presence of salt at physiological ionic strength.

A number of polyplexes have been shown to induce cellular uptake through chargemediated interaction with the negative charge of the plasma membrane. ${ }^{1}$ Zeta potential, which represents the surface charge of nanoparticles, is another factor that can influence cellular uptake. P67-51, with the highest MW in this series, formed nanoparticles with much higher zeta potential than the others with similar net positive charge density (Figure 3 ). This result is consistent with the compaction ability of the polymers with similar charge density. The compaction ability of P67-51 is much higher than the rest three. On the other hand, the zeta potential of the PPA/DNA nanoparticles increased with the increase of charge density of PPA carrier.

\section{Cellular uptake of PPA-DNA nanoparticles}

At the cellular level, cellular uptake is the first obstacle encountered by polymer/DNA nanoparticles. We here examined cellular uptake of various PPA/DNA nanoparticles by flow cytometry in HeLa and HEK293 cells. Nanoparticles were prepared with YOYO-1 iodide-labeled DNA. In Figure 4, we plotted the arithmetic average relative fluorescence intensity of all gated cells at $37^{\circ} \mathrm{C}$, which represented the relative cellular uptake plus nonspecific absorption of particles on cell surface, subtracted by fluorescence intensity at $4{ }^{\circ} \mathrm{C}$, which represented the amount of surface-adsorbed particles. Compared with naked DNA, which average intensity is negligible, cell uptake mediated by nanoparticles had a dramatic increase. In the case of HeLa calls (Figure 4a), the average intensity of P10-49/DNA nanoparticles was much lower than other nanoparticles made from PPAs with similar net positive charge densities but higher MWs. On the other hand, cell uptake increased with the increase of net positive charge density of PPAs, with P31-65/DNA nanoparticles showing the highest level of uptake.

Cellular uptake of nanoparticles can be correlated with the average size and zeta potential of the nanoparticles. In general, nanoparticles with smaller size and higher zeta potential were more likely to be taken up by cells. For example, the lower cellular uptake of P10-49 nanoparticle may be attributed to the lower zeta potential and the larger size in physiological medium. The highly charged P67-51/DNA nanoparticles, however, did not yield high level of uptake in HeLa cells, likely because of their relatively larger size in salt solution. P31-65/ DNA nanoparticles had the highest zeta potential and smallest particle size, which led to the highest cellular uptake in HeLa. The uptake of PEI/DNA nanoparticles was relatively low in HeLa. This may be the result of larger size of PEI/DNA nanoparticle in physiological salt condition. 
Cellular uptake of nanoparticle in HEK293 cells (Figure 4b) was different with that in HeLa cells. There was no significant difference in uptake when MW of PPA was larger than 25 $\mathrm{kDa}$ no matter what charge density was. P10-49 and PEI/DNA nanoparticles had much lower uptake level than the others. The reason might be that the uptake of HEK293 cell was not sensitive to zeta potential of nanoparticles at this level. The dramatically increased sizes in the presence of salt solution (Figure 2) led to the low level of uptake. In HepG2 cells, all the PPA nanoparticles did not show significant difference in uptake level (Figure 4c). These results implied that uptake of nanoparticle was cell dependent, and other intracellular trafficking factors may be the rate limiting steps affecting the transfection efficiency.

\section{Buffering capacity of PPAs}

Buffering capacity is an important feature of cationic polymers, as set out in the "proton sponge" hypothesis, ${ }^{10}$ by facilitating the endosomal escape of polyplexes to mediate efficient gene expression. Figure 5 showed that P10-49, P15-50 and P27-50 had similar protonation behavior, which implied that PPAs with similar charge density had similar buffering capacities in spite of the increase of MW. Comparing the curves of P27-50 and P31-65, the buffering capacity had a slight increase as the net positive charge density increased from 0.49 for P27-50 to 0.94 for P31-65. In contrast, the buffering capacity of PEI (22\%) was much more pronounced comparing with P31-65 (8\%) and all other PPAs (negligible). This observation suggested that the buffering capacity was not the main contributing factor to PPA/DNA nanoparticle-mediated transfection.

\section{Complex stability of PPA/DNA nanoparticles against dextran sulfate}

The complex stability of the nanoparticles was investigated by incubating EtBr stained PPA/ DNA nanoparticles with a competing polyanion, dextran sulfate (MW $500 \mathrm{kDa}) .{ }^{31,34} \mathrm{PPA} /$ DNA nanoparticles may be dissociated by the competing polyanion at sufficiently high concentration. The released or loosened DNA binds with EtBr then produces fluorescence. Thus dissociation degree of the nanoparticles can be monitored by the fluorescence intensity. The complex stability of nanoparticles can be reflected by the fluorescence intensity as a function of dextran sulfate concentration.

Figure 6a showed the complex stability of nanoparticles prepared by PPAs with different MWs and similar net positive charge densities. When the MW was lower than $27 \mathrm{kDa}$, the stability of nanoparticle was similar. When the MW increased to $67 \mathrm{kDa}$, the stability of nanoparticles was significantly higher. Figure $6 \mathrm{~b}$ showed the effect of net positive charge density on complex stability. The differences among these three polymers were significant, and the stability of the nanoparticles increased with the increase of net positive charge density. P31-65 nanoparticles showed the highest stability among all nanoparticles tested, including PEI.

\section{In vitro transfection efficiency of PPA/DNA nanoparticles}

The in vitro transfection efficiency was investigated in HeLa, HEK293 and HepG2 cell lines using luciferase as a reporter gene. The transfection efficiency exhibited a strong correlation with the MW and charge density of the PPA gene carriers; and the results in all three cell lines were consistent. When the MW increased from $10 \mathrm{kDa}$ to $67 \mathrm{kDa}$ at a fixed net positive charge density ( 0.5), the transgene expression level increased by 46, 230 and 283 times in HeLa, HEK293 and HepG2, respectively, at N/P ratio of 10 (Figure 7). On the other hand, at the same N/P ratio, when the net positive charge density increased from 0.49 to 0.94 , the luciferase expression level increased by 141, 61 and 158 times in the same three cell lines, respectively. The same trends were observed for nanoparticles prepared at N/P ratio of 16 . 
Endolysosomal escape has been identified as an important step in successful nanoparticlemediated transfection. ${ }^{10}$ Here we investigated the effect of treatment with chloroquine diphosphate (CQ), an efficient endosome disruption reagent, on PPA/DNA nanopartilcemediated transfection. Since most of the PPAs tested in this series exhibited low levels of buffering capacity as shown above, we anticipate significant increase in transfection efficiency with PPA/DNA nanoparticles in the presence of CQ. We conducted this experiment with $50 \mu_{\mathrm{M}}$ of CQ, because a minimal cytotoxicity was oberved at this concentration. Since CQ also carries positive charge and may compete with polycations, we added CQ after 4 hours of transfection. The transfection efficiencies of PPA/DNA nanoparticles increased significantly in the presence of CQ, but at various degrees (Figure 8). Among all nanoparticles tested, P27-50/DNA nanoparticles showed 80-fold improvement in transgene expression in the presence of CQ, whereas P10-49/DNA nanoparticles yielded about 1,000-fold higher transgene expression level. Since P27-50 had similar buffering capacity with P10-49, the increase in transfection efficiency may be attributed to the higher DNA compaction ability of P27-50, and hence higher level of protection to encapsulated DNA from the endolysosomal degradation. Consistent with this notion, the transfection efficiency of P31-65/DNA nanoparticles increased by only 8 times in the presence of CQ, since P31-65 showed the highest level of compaction ability.

On the other hand, PEI/DNA nanoparticle yielded much smaller enhancement (about 3-fold higher) in transfection efficiency in the presence of CQ as a result of its strong buffering capacity. Previous literature also reported that chloroquine did not significantly improve the transfection efficiency of PEI. ${ }^{35}$ This small discrepancy may be caused by the differences in CQ concentration and cell type. Comparing with PEI/DNA nanoparticles, the lower buffering capacity of P31-65 was compensated by its higher DNA compaction capacity and higher cellular uptake of P31-65/DNA nanoparticles, resulting in comparable level of transfection efficiency as PEI/DNA nanoparticles. In general, this experiment demonstrated that the endosomal escape is a significant barrier to PPA/DNA nanoparticle-mediated transfection, particularly to PPAs with lower DNA compaction ability. Improving their endolysomal escape ability should significantly increase the transfection efficiency of PPA/ DNA nanoparticles.

The luciferase expression combined with cellular uptake experiments (Figure 4) demonstrated that the molecular weight and charge density of the polycation did not significantly influence initial cellular entry, but rather plays an important role during intracellular trafficking steps. Since both structural parameters influence the binding ability of a polycation toward plasmid DNA, it is important and feasible to balance the intracellular release of DNA and the protection of DNA from degradation by fine-tuning these parameters. ${ }^{17,} 36$ Higher protection ability of polymeric carrier will lead to lower level of DNA release in cytosol and neuclus, and vice versa. In our study, however, PPA polymers with higher protection ability mediated higher transfection efficiency, which implied that the cytosolic release of DNA from PPA/DNA nanoparticles was not one of the rate limiting steps for these nanoparticle-mediated transfection. These results are consistent with our previous findings on efficient DNA unpacking in cytosol, even though the mechanism of DNA unpacking and intracellular trafficking remains elusive.

\section{Cytotoxicity of PPA/DNA nanoparticles}

The cytotoxicity of the nanoparticles was investigated using WST-1 assay. The cells were treated at the same transfection condition as described in Figure 7. As Figure 9 suggested, the viability of cells treated with all polymer/DNA nonaparticles was around 100\%, which implied that cytotoxocity was not a contributing factor to differences in transfection efficiency observed in this study. Although PEI is known to be cytotoxic in many cell lines, 
because the low toxicity observed here may be due to the relatively low dose of nanoparticles used in this study.

\section{Conclusion}

Using PPA as a model system, we demonstrated that the MW and net positive charge density of the gene carrier significantly influence the physicochemical properties and the transfection efficiency of PPA/DNA nanoparticles. An increase in MW and/or net positive charge density of PPA carrier yielded higher DNA compaction capacity, smaller nanoparticles with higher surface charges, and higher complex stability against challenges by salt and polyanions. These favorable physicochemical properties of nanoparticles led to higher level of cellular uptake in HeLa and transfection efficiency in several cell lines. In addition, PPA/DNA nanoparticles showed varying levels of enhancement in transgene expression in the presence of CQ due to the minimal levels of buffering capacity observed for these carriers. PPA/DNA nanoparticles with higher stability showed lower level of CQinduced improvement because they rendered higher level of protection to DNA. PPA/DNA nanoparticles with the highest complex stability showed comparable transfection efficiency as PEI/DNA nanoparticles likely by compensating the lower buffering capacity with higher levels of cellular uptake and protection to DNA in endolysosomal compartment. Lastly, the differences in transfection efficiency were not attributed by any difference in cytotoxicity among the carriers, as all nanoparticles showed minimal level of cytotoxicity under the transfection conditions.

\section{Acknowledgments}

This study was supported by the National Institutes of Health, National Institute of General Medical Sciences under the grant GM073937.

\section{References}

1. Wong SY, Pelet JM, Putnam D. Prog. Polym. Sci 2007;32:799-837.

2. Mao HQ, Leong KW. Adv. Genet 2005;53:275-306. [PubMed: 16240998]

3. Kim EJ, Shim G, Kim K, Kwon IC, Oh YK, Shim CK. J. Gene Med 2009;11:791-803. [PubMed: 19569085]

4. Fukushima S, Miyata K, Nishiyama N, Kanayama N, Yamasaki Y, Kataoka K. J. Am. Chem. Soc 2005;127:2810-2811. [PubMed: 15740090]

5. Miyata K, Oba M, Nakanishi M, Fukushima S, Yamasaki Y, Koyama H, Nishiyama N, Kataoka K. J. Am. Chem. Soc 2008;130:16287-16294. [PubMed: 19006313]

6. Demeneix B, Behr JP. Adv. Genet 2005;53:217-230. [PubMed: 16240995]

7. Jere D, Xu CX, Arote R, Yun CH, Cho MH, Cho CS. Biomaterials 2008;29:2535-2547. [PubMed: 18316120]

8. Mao HQ, Roy K, Troung-Le VL, Janes KA, Lin KY, Wang Y, August JT, Leong KW. J. Control. Release 2001;70:399-421. [PubMed: 11182210]

9. Wang J, Mao HQ, Leong KW. J. Am. Chem. Soc 2001;123:9480-9481. [PubMed: 11562246]

10. Pack DW, Hoffman AS, Pun S, Stayton PS. Nat. Rev. Drug Discov 2005;4:581-593. [PubMed: 16052241]

11. Reineke TM, Davis ME. Bioconjug. Chem 2003;14:255-261. [PubMed: 12526716]

12. Reineke TM, Davis ME. Bioconjug. Chem 2003;14:247-254. [PubMed: 12526715]

13. Sharma R, Lee JS, Bettencourt RC, Xiao C, Konieczny SF, Won YY. Biomacromolecules 2008;9:3294-3307. [PubMed: 18942877]

14. Wong SY, Sood N, Putnam D. Mol. Ther 2009;17:480-490. [PubMed: 19142180]

15. Wang RB, Zhou LZ, Zhou YF, Li GL, Zhu XY, Gu HC, Jiang XL, Li HQ, Wu JL, He L, Guo XQ, Zhu BS, Yan DY. Biomacromolecules 2010;11:489-495. [PubMed: 20047311] 
16. Strand SP, Issa MM, Christensen BE, Varum KM, Artursson P. Biomacromolecules 2008;9:32683276. [PubMed: 18834173]

17. Layman JM, Ramirez SM, Green MD, Long TE. Biomacromolecules 2009;10:1244-1252. [PubMed: 19331402]

18. Nemoto Y, Borovkov A, Zhou YM, Takewa Y, Tatsumi E, Nakayama Y. Bioconjug Chem 2009;20:2293-2299. [PubMed: 19899789]

19. Bauhuber S, Hozsa C, Breunig M, Gopferich A. Adv. Mater 2009;21:3286-3306. [PubMed: 20882498]

20. Luten J, van Nostruin CF, De Smedt SC, Hennink WE. J. Control. Release 2008;126:97-110. [PubMed: 18201788]

21. Yu H, Russ V, Wagner E. AAPS J 2009;11:445-455. [PubMed: 19504187]

22. Sato T, Ishii T, Okahata Y. Biomaterials 2001;22:2075-2080. [PubMed: 11432586]

23. Fischer D, Bieber T, Li YX, Elsasser HP, Kissel T. Pharmaceutical Research 1999;16:1273-1279. [PubMed: 10468031]

24. Kiang T, Wen H, Lim HW, Leong KW. Biomaterials 2004;25:5293-5301. [PubMed: 15110480]

25. Lee CC, Liu Y, Reineke TM. Bioconjugate Chemistry 2008;19:428-440. [PubMed: 18197609]

26. Wang J, Zhang PC, Mao HQ, Leong KW. Gene Ther 2002;9:1254-1261. [PubMed: 12215893]

27. Wang J, Huang SW, Zhang PC, Mao HQ, Leong KW. Int. J. Pharm 2003;265:75-84. [PubMed: 14522120]

28. Wang J, Zhang PC, Lu HF, Ma N, Wang S, Mao HQ, Leong KW. J. Control. Release 2002;83:157-168. [PubMed: 12220847]

29. Zhang PC, Wang J, Leong KW, Mao HQ. Biomacromolecules 2005;6:54-60. [PubMed: 15638504]

30. Osullivan MC, Dalrymple DM. Tetrahedron Lett 1995;36:3451-3452.

31. Zhang XQ, Wang XL, Zhang PC, Liu ZL, Zhuo RX, Mao HQ, Leong KW. J. Control. Release 2005;102:749-763. [PubMed: 15681095]

32. Read, ML.; Bettinger, T.; Oupicky, D. Nonviral Vectors for Gene Therapy Methods and Protocols. 1st ed.. Findeis, MA., editor. Humana Press; Totowa, New Jersey: 2001. p. 131

33. Zauner W, Farrow NA, Haines AM. J. Control. Release 2001;71:39-51. [PubMed: 11245907]

34. Pichon C, Goncalves C, Midoux P. Adv. Drug Deliv. Rev 2001;53:75-94. [PubMed: 11733118]

35. Akinc A, Thomas M, Klibanov AM, Langer R. J Gene Med 2005;7:657-663. [PubMed: 15543529]

36. Liu YM, Reineke TM. Bioconjug. Chem 2006;17:101-108. [PubMed: 16417257]

Biomacromolecules. Author manuscript; available in PMC 2011 January 15. 


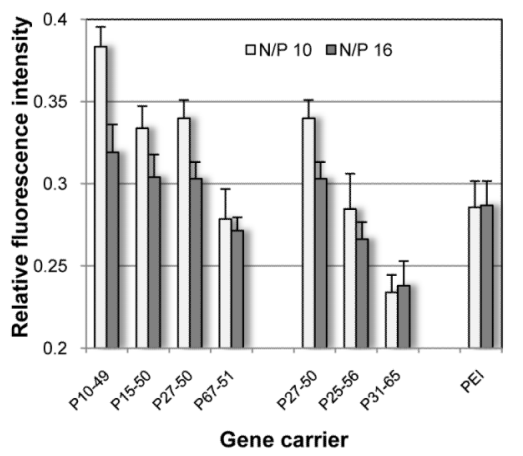

Figure 1.

DNA compaction ability of PPA carriers measured by relative fluorescence intensity in reference to that of naked plasmid DNA. 

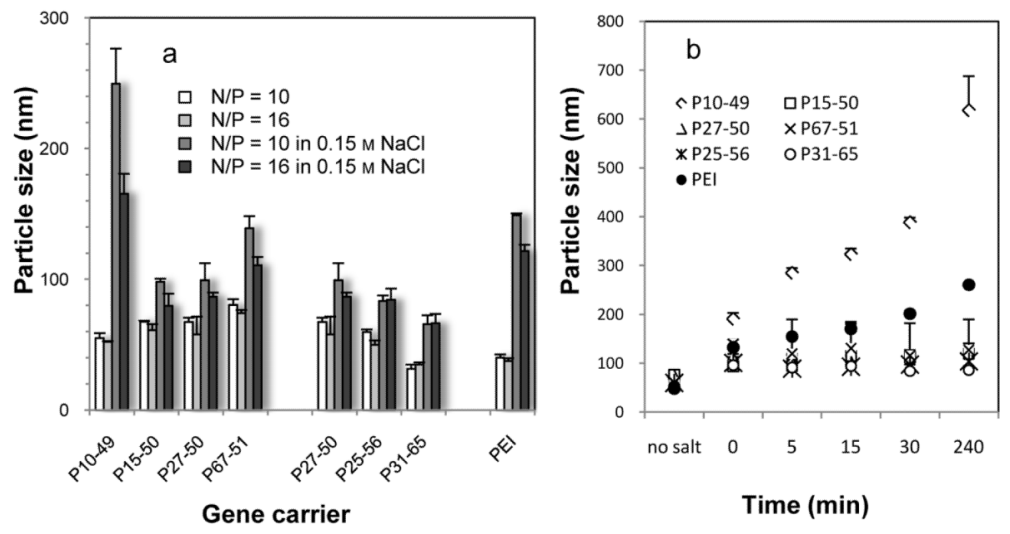

Figure 2.

The average size of PPA/DNA nanoparticles in DI water and in 0.15 м NaCl solution (a) and the change in particle size (N/P 10) to salt challenge as function of time (b). Nanoparticles were prepared from PPAs with different molecular weights or different net positive charge densities. 


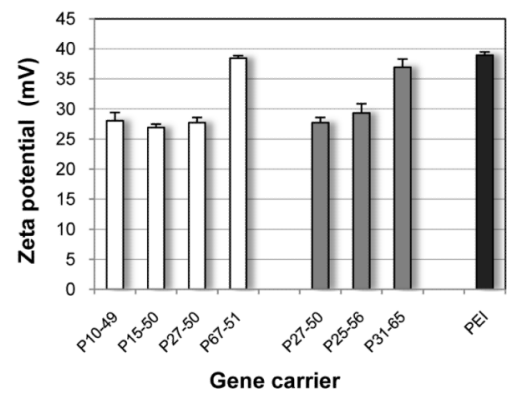

Figure 3.

Zeta potential of PPA/DNA nanoparticles in DI water. Nanoparticles were prepared at N/ $\mathrm{P}=10$ with PPAs with different MWs and net positive charge densities. 


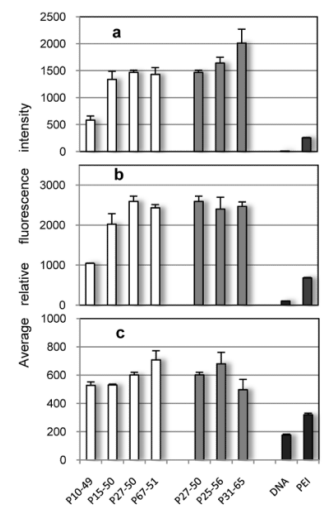

Figure 4.

Cellular uptake of PPA/DNA nanoparticles. DNA was labeled with YOYO-1 iodide at ratio of 1 dye per 50 base pairs. Cellular uptake was conducted in HeLa (a), HEK293 (b) and HepG2 (c) at a dose of $2 \mu \mathrm{g}$ DNA for $4 \mathrm{~h}$, either at $37{ }^{\circ} \mathrm{C}$ or at $4{ }^{\circ} \mathrm{C}$. Cell uptake was quantified by flow cytometry and a minimum of 10,000 events per sample were collected for analysis. 


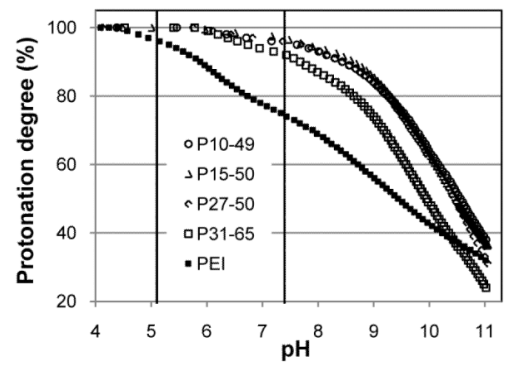

Figure 5.

Protonation behavior of PPAs. An amount equal to $0.1 \mathrm{mmol}$ of amine groups of PPAs was dissolved in $5 \mathrm{~mL}$ of $0.15 \mathrm{~m} \mathrm{NaCl}$ solution. The $\mathrm{pH}$ of polymer solutions was initially set to $\mathrm{pH} 11.0$ by 2 м $\mathrm{NaOH}$ and titrated to $\mathrm{pH} 3.0$ using 0.1 м $\mathrm{HCl}$. 


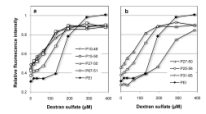

Figure 6.

Complex stability of PPA/DNA nanoparticles against the challenge of dextran sulfate. Nanoparticle suspension $(20 \mu \mathrm{L})$ containing $1 \mu \mathrm{g}$ of DNA was incubated with dextran sulfate solution $(20 \mu \mathrm{L}, 500 \mathrm{kDa})$ with different concentrations and ethidium bromide (60 $\mu \mathrm{L}, 5 \mu \mathrm{g} / \mathrm{mL}$ in PBS). 


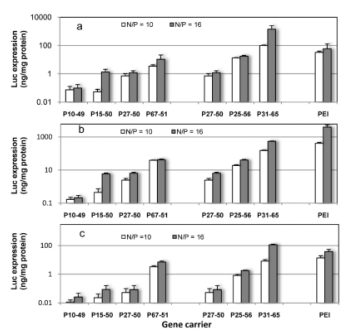

Figure 7.

Transfection efficiency of PPA/DNA nanoparticles prepared from PPAs with different MWs or net positive charge densities in HeLa (a), HEK293 (b) and HepG2 (c) cell lines. Cells (HeLa: 4×10\%/well, HEK293: 1.4×10\%/well, HepG2: $1 \times 10^{5} /$ well) were seeded 24 h prior to transfection. Nanoparticles were added at a dose of $2 \mu \mathrm{g}$ of plasmid DNA per well in complete medium. After $4 \mathrm{~h}$ of transfection, medium was replenished and incubated for 2 days before luciferase assay. 


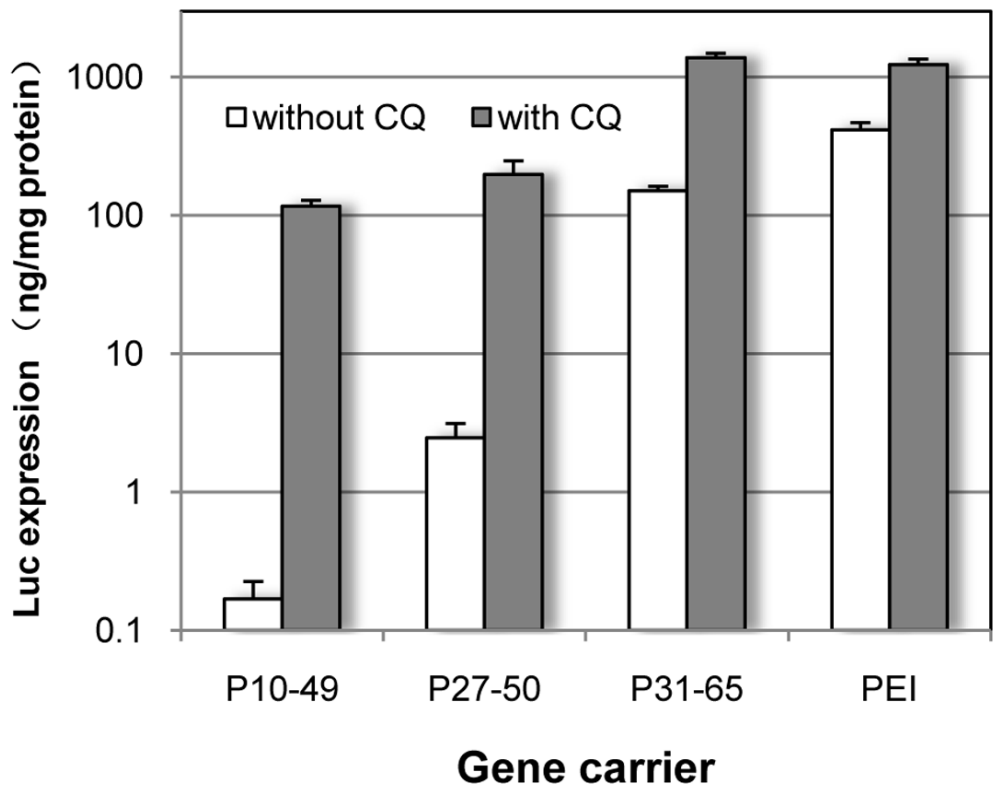

Figure 8.

Transfection efficiency of PPA/DNA nanoparticles $(\mathrm{N} / \mathrm{P}=10)$ with or without chloroquine (CQ). Trancfection was conducted in HEK 293 cells at a density of $140 \mathrm{~K} /$ well. After $4 \mathrm{~h}$ of transfection, medium containing $50 \mu_{\mathrm{M}} \mathrm{CQ}$ was replenished and cells were incubated for 2 days before luciferase assay. 


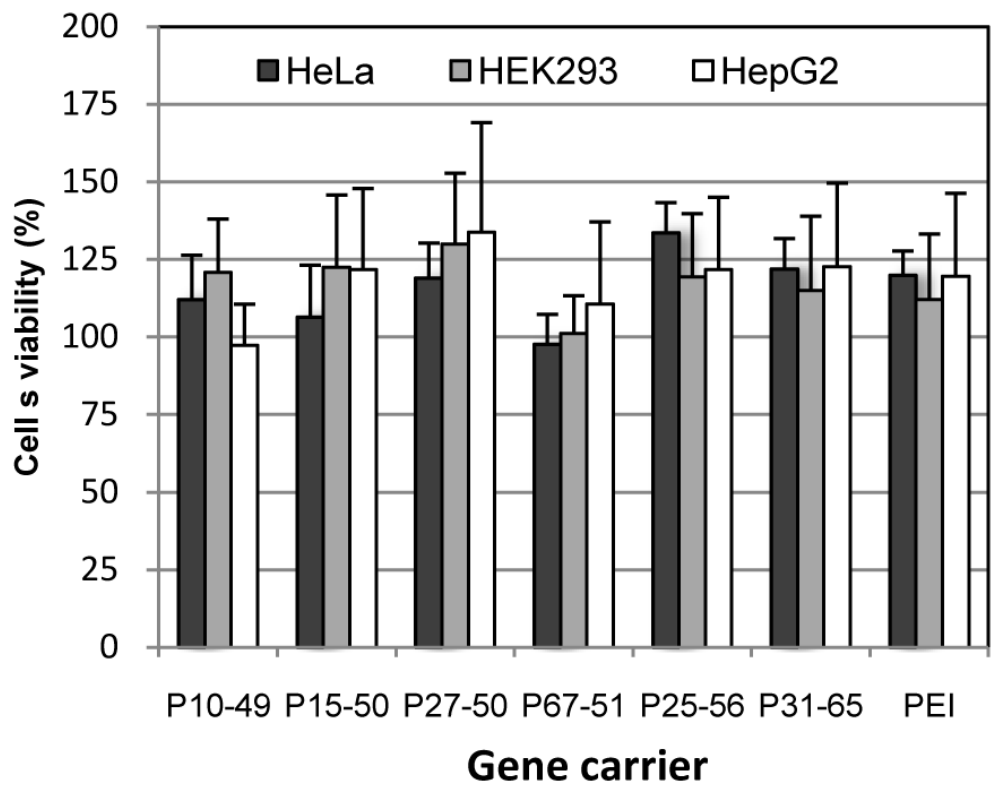

Figure 9.

Cell viability of polymer/DNA nanoparticles in reference to untreated group under the transfection condition. HeLa, HEK293 and HepG2 cells were treated with polymer/DNA nanoparticles at a dose of $2 \mu \mathrm{g}$ DNA per $4 \times 10^{4}, 1.4 \times 10^{5}$ or $1 \times 10^{5}$ cells. The cells were incubated for $4 \mathrm{~h}$ before WST-1 assay. 


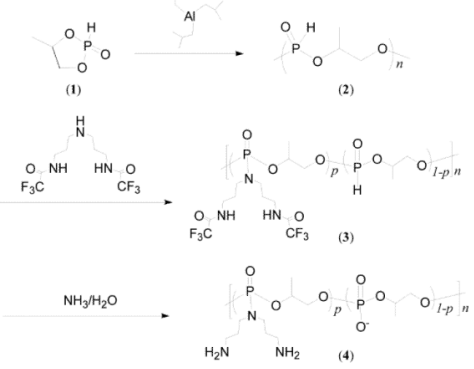

Scheme 1.

Synthesis of PPAs with dipropyltriamine side chain. The grafting degree of PPA is defined by the percentage of repeating units conjugated with DPA side chain. The net positive charge density is defined by the number of net positive charge per repeating unit, which can be calculated by $3 p-1$. 
